\title{
Heart Rate Variability and Inflammatory Response in Rats With Lipopolysaccharide-Induced Endotoxemia
}

\author{
I. ZILA ${ }^{1}$, D. MOKRA ${ }^{1}$, J. KOPINCOVA ${ }^{1}$, M. KOLOMAZNIK ${ }^{1}$, M. JAVORKA ${ }^{1}$, \\ A. CALKOVSKA ${ }^{1}$ \\ ${ }^{1}$ Department of Physiology and Martin Biomedical Centre, Jessenius Faculty of Medicine \\ in Martin, Comenius University in Bratislava, Slovak Republic
}

Received March 27, 2015

Accepted June 30, 2015

On-line December 15, 2015

\section{Summary}

The aim of the study was to evaluate short-term heart rate variability (HRV) as an index of cardiac autonomic control in rats with lipopolysaccharide (LPS)-induced endotoxemia. Animals were injected intraperitoneally with LPS (100 $\mu \mathrm{g} / \mathrm{kg}$ b.w.) and control group with an equivalent volume of saline. ECG recordings were done before (base) and 60, 120, 180, 240 and $300 \mathrm{~min}$ after LPS or saline administration. HRV magnitude was quantified by time and frequency-domain analysis (mean RR interval, SDRR, RMSSD, spectral powers in low (LF) and high frequency (HF) bands. Heart tissue homogenates and plasma were analyzed to determine interleukin 6 (IL-6), tumor necrosis factor alpha (TNF-a) and oxidative stress level (TBARS). Administration of lipopolysaccharide was followed by continuous rise in colonic body temperature compared to saline-treated controls. Endotoxemia in rats was accompanied by significant decrease in HRV spectral activity in high-frequency range at maximal body temperature (logHFpower: $1.2 \pm 0.5$ vs. $1.9 \pm$ $\left.0.6 \mathrm{~ms}^{2}, \mathrm{P}<0.01\right)$. Increased IL-6 was found in heart tissue homogenates of LPS rats $(8.0 \pm 0.6$ vs. $26.4 \pm 4.8 \mathrm{pg} / \mathrm{ml},(P<0.05)$. In conclusions, reduced HRV in HF band may indicate a decreased parasympathetic activity in LPS-induced endotoxemia as basic characteristics of altered cardiac control during response to endotoxemia.

\section{Key words}

Heart rate variability - Interleukin 6 • Lipopolysaccharide • Endotoxemia • Autonomic nervous system • Rat model

\section{Corresponding author}

A. Calkovska, Department of Physiology and Martin Biomedical Centre, Jessenius Faculty of Medicine, Comenius University, Mala Hora 4, SK-03601 Martin, Slovakia.

E-mail: calkovska@jfmed.uniba.sk

\section{Introduction}

Heart rate variability (HRV), "beat-to-beat" oscillations of the heart rate around its mean value, represents physiological phenomenon determined predominantly by the autonomic nervous system (ANS) control. Therefore, the measurement of the HRV is a noninvasive technique that can be used to investigate the dynamic balance between sympathetic and vagal activity. It has been proven to be very useful in humans for research and clinical studies regarding the cardiovascular diseases, somatic and psychiatric disorders (Borell et al. 2007, Javorka et al. 2008, Tonhajzerova et al. 2012). Measurement of HRV has also been used in animal models to analyze changes in the ANS (Matthew et al. 2004, Mokra et al. 2008, Fairchild et al. 2009).

HRV is traditionally quantified by linear methods - time and frequency (spectral) domain analyses, which provide information about quantitative characteristic of the heart rate oscillations - the HRV magnitude. The time domain analysis is based on the normal-to-normal (NN) interval, or the time difference between successive QRS complexes (RR interval). In contrast, the spectral analysis allows to isolate the faster high frequency respiratory-linked oscillations (HF-HRV) 
from slower oscillations around $0.1 \mathrm{~Hz}$ (LF-HRV) (Malik et al. 1996). In humans, the high-frequency cardiac rhythms are mediated primarily by vagal innervation of the sinoatrial node reflecting the respiratory sinus arrhythmia (RSA), a physiological phenomenon characterized by the heart rate increase during inspiration and decrease during expiration (Akselrod et al. 1981). In contrast, the physiological mechanism contributing to the LF-HRV is still discussed; it could reflect baroreflexmediated changes (Goldstein et al. 2011). In animal studies, it is necessary to adjust the specific frequency ranges of HRV spectral bands for different animal species. It was shown that the analysis of HRV is a sensitive method to study ANS activity in animals and to detect discrete changes in sympathetic-vagal balance, particularly in vagal function (Mokra et al. 2008, 2013).

The autonomic nervous system and the inflammatory response are intimately linked (Kox et al. 2011). The acute response to endotoxemia includes activation of innate immune mechanisms as well as changes in autonomic nervous activity (Tracey 2002). Sympathetic and vagal nerves are thought to have antiinflammation functions (Rosas-Ballina et al. 2008, Straub et al. 2008). HRV assessment has been suggested to provide insights into the acute effect of sympathetic and cholinergic anti-inflammatory pathways. Recently, several studies have demonstrated that central nervous system can decrease cytokine production via parasympathetic activity (Mioni et al. 2005, van Westerloo et al. 2006).

The objective of the study was to evaluate HRV parameters as the markers of autonomic control during LPS-induced endotoxemia and to investigate association between proinflammatory markers and acute-phase proteins and autonomic nervous system activity.

\section{Methods}

Animals

The experiments were performed on 28 adult male rats (Wistar) with a mean body mass of $347 \pm 6 \mathrm{~g}$ (mean $\pm \mathrm{SEM}$ ).

\section{Material}

Lipopolysaccharide (LPS): purified lyophilized phenol extract of Escherichia coli (026:B6, Sigma) was dissolved in sterile saline and frozen in aliquots. Before use, the LPS was diluted in sterile saline and injected intraperitoneally.

\section{Design of the study}

The study was performed with accordance to EU Directive 2010/63/EU for animal experiments and approved by the Local Ethics Commitee of the Jessenius Faculty of Medicine, Comenius University in Martin. The model is described elsewhere (Zila et al. 2012). Briefly, the animals were anesthetized with a mixture of $600 \mathrm{mg} \cdot \mathrm{kg}^{-1}$ urethane and $60 \mathrm{mg} \cdot \mathrm{kg}^{-1} \quad \alpha$-chloralose intraperitoneally. They were tracheotomized and breathed spontaneously through a tracheal tube. The airflow was recorded through the Fleisch head of a pneumotachograph connected to the tracheal tube and tidal volume $\left(\mathrm{V}_{\mathrm{T}}\right)$ was obtained by electronic integration of the airflow signal (ADInstruments Pty Ltd.). The polyethylene catheter inserted into the femoral artery was used for arterial blood pressure monitoring and blood samples withdrawal. Blood gases $\left(\mathrm{PaO}_{2}, \mathrm{PaCO}_{2}\right)$ and $\mathrm{pH}$ analysis was performed using a blood gas analyzer (Rapidlab; Bayer Diagnostics, Germany) and values were corrected for actual body temperature. Colonic body temperature $\left(T_{c}\right)$ was continuously measured with thermocouple (MiniLogger) inserted $4-5 \mathrm{~cm}$ into the anus.

\section{Experimental protocol}

The animals were randomly divided into two groups. Animals of LPS group $(\mathrm{n}=13)$ received intraperitoneally LPS $\left(100 \mu \mathrm{g} \cdot \mathrm{kg}^{-1}\right)$ and control group $(n=15)$ received an equivalent volume of sterile saline. All recordings were done before (base) and 60, 120, 180, 240 and 300 min after LPS or saline administration.

ECG was recorded by means of needle subcutaneous electrodes. Signal of R-R intervals was transferred to the computer through VarCorPF (Sima Media, Czech Republic). The 300 R-R intervals segments were analyzed between the first and fifth minutes of each recording interval (base, 60, 120, 180, 240 and $300 \mathrm{~min}$ after LPS or saline administration).

\section{Data analysis}

\section{Time domain analysis}

We evaluated the mean R-R interval (ms), SDNN - the standard deviation of R-R intervals (ms) as a marker of the overall magnitude of HRV and RMSSD (the root-mean-square successive beat-to-beat differences in $\mathrm{ms}$ ) reflecting the average magnitude of changes between two consecutive beats and regarded as a marker of vagal heart rate control. 


\section{Frequency domain analysis}

Before analysis, the slower oscillations were eliminated using the detrending procedure of Tarvainen $e t$ al. (2002) and time series were resampled to obtain equidistant time series using cubic spline interpolation. Subsequently, mean power spectra were computed by fast Fourier transform (window length of 256 samples).

The spectral powers were quantified in two frequency bands: low frequency band (LF: 0.2-0.8 Hz) which is determined by both the sympathetic and parasympathetic activity. High frequency band $(>0.8 \mathrm{~Hz})$ reflecting mainly respiratory sinus arrhythmia as an index of cardiac vagal control.

Assays

Concentration of thiobarbituric-acid reactive substances (TBARS) in the plasma at the end of experiment was determined from the absorbance at $532 \mathrm{~nm}$ and expressed in $\mathrm{nmol} / \mathrm{mg}$ protein.

Investigation of IL-6 and aldosterone were carried out in plasma and heart tissue homogenates by commercial Rat ELISA kits (BlueGene Biotech, Shanghai, China). The levels of TNF- $\alpha$ were determined in plasma by commercially available ELISA kits (CloudClone Corp., Houston, USA).

For plasma determination, blood sample was collected at the end of experiment with heparin as anticoagulant and centrifuged for $15 \mathrm{~min}$ at $1000 \mathrm{~g} / 4^{\circ} \mathrm{C}$; plasma had been removed and stored at $-80{ }^{\circ} \mathrm{C}$.

For homogenate determination, heart tissue had been cut to small pieces and homogenized in ice-cold
PBS (0.02 mol/1, pH 7.2) to form $10 \%$ homogenates. According to manufacturer's instructions, resulting suspension was subjected to two freeze-thaw cycles and immediately centrifuged for $15 \mathrm{~min}$ at $1500 \mathrm{~g}$. Supernatant was removed and stored at $-80^{\circ} \mathrm{C}$.

\section{Statistical analysis}

The statistical software package SYSTAT 6.0.1 (SPSS Inc., 1996) was used for data analysis. Because absolute values of linear HRV analysis indices differ greatly among individuals, the frequency-domain HRV parameters were logarithmically transformed for statistical testing. Data were tested for normality of distribution using Kolmogorov-Smirnov test. Due to nonGaussian distribution of analyzed data (despite of logtransformation of spectral measures) we used nonparametric tests for statistical analysis. Between-group differences were analyzed using Mann-Whitney test, and Wilcoxon test was used for testing of within-group differences - baseline vs. other analyzed intervals. Data are expressed as means \pm SEM, differences are considered significant at $\mathrm{P}<0.05$.

\section{Results}

Administration of lipopolysaccharide was accompanied by continuous rise in colonic body temperature compared to saline-treated controls. The intraperitoneal injection of $100 \mu \mathrm{g} \cdot \mathrm{kg}^{-1}$ induced monophasic thermogenic reaction in all animals with peak registered 300 min after LPS administration (Fig. 1).

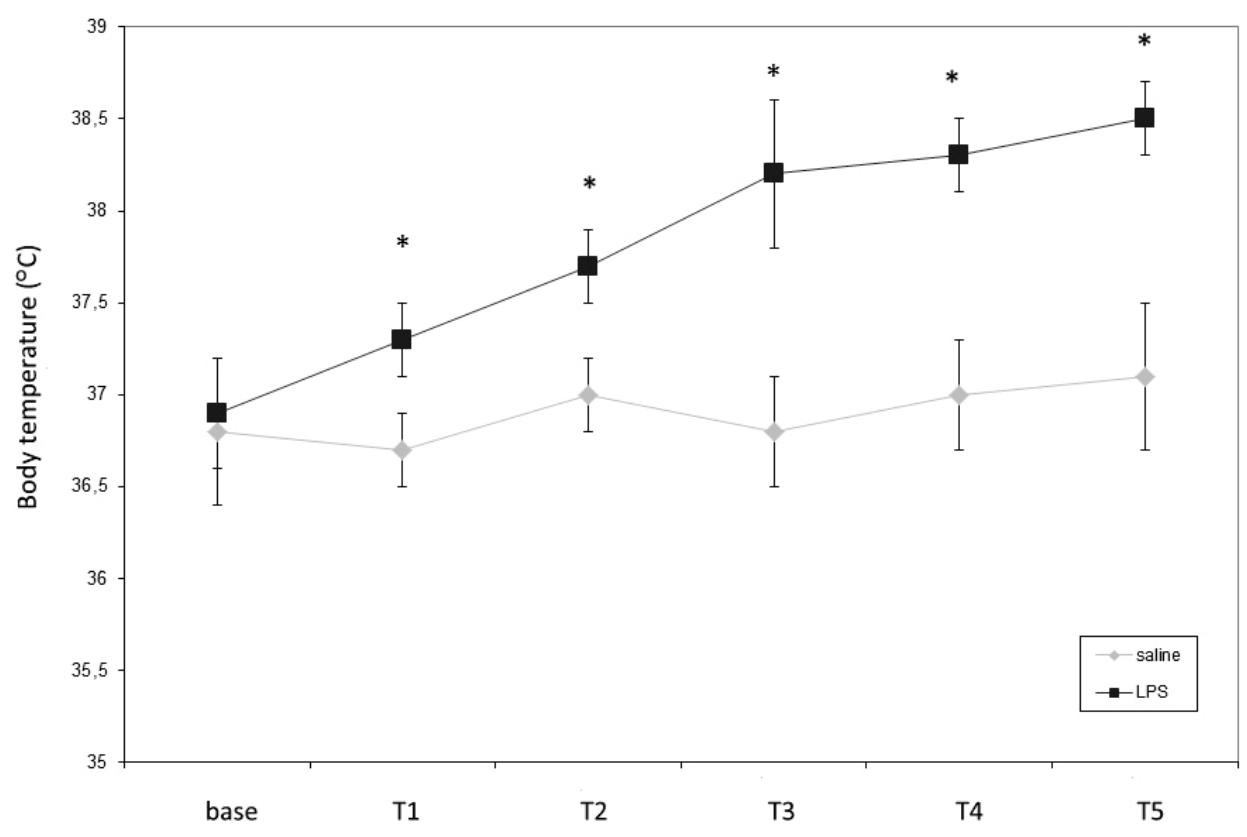

Fig. 1. Colonic body temperature $\left({ }^{\circ} \mathrm{C}\right)$ measured before saline/LPS administration (base) and 60 (T1), 120 (T2), 180 (T3), 240 (T4) and 300 (T5) min after saline/LPS administration. * $\mathrm{P}<0.05$. 


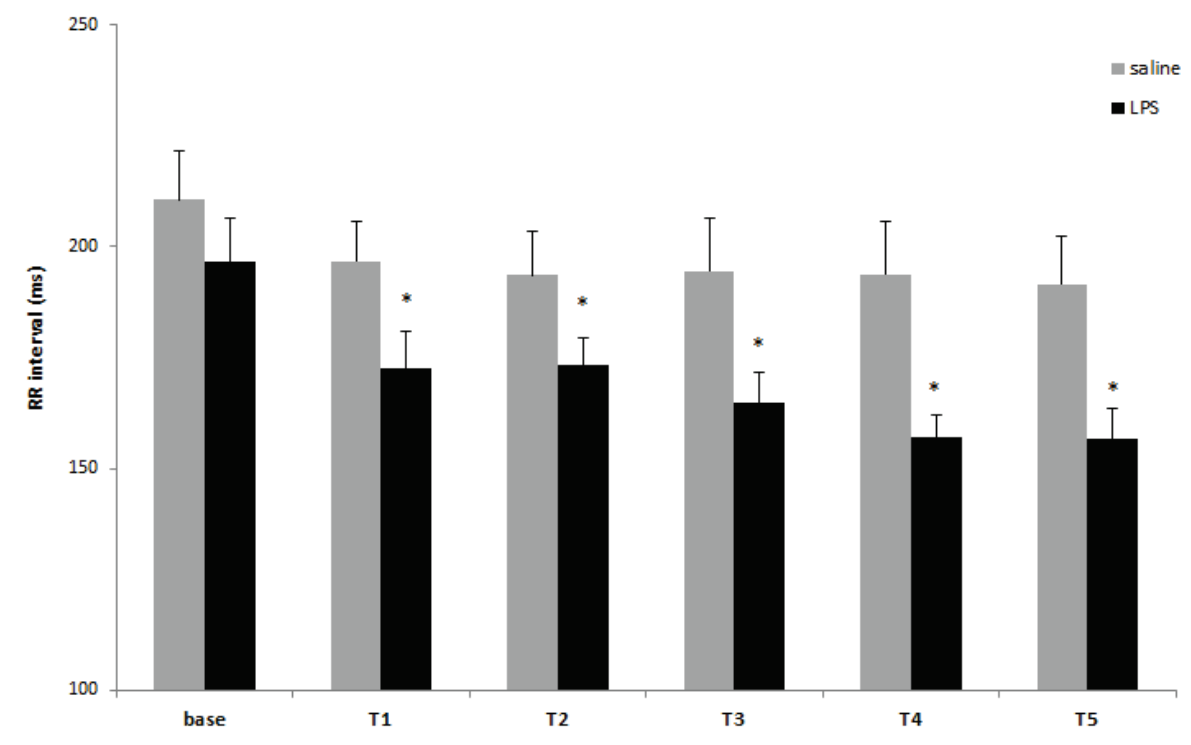

Fig. 2. Mean duration of $R-R$ intervals before saline/LPS administration (base) and 60 (T1), 120 (T2), 180 (T3), 240 (T4) and 300 (T5) after saline/LPS administration. $* \mathrm{P}<0.05$.
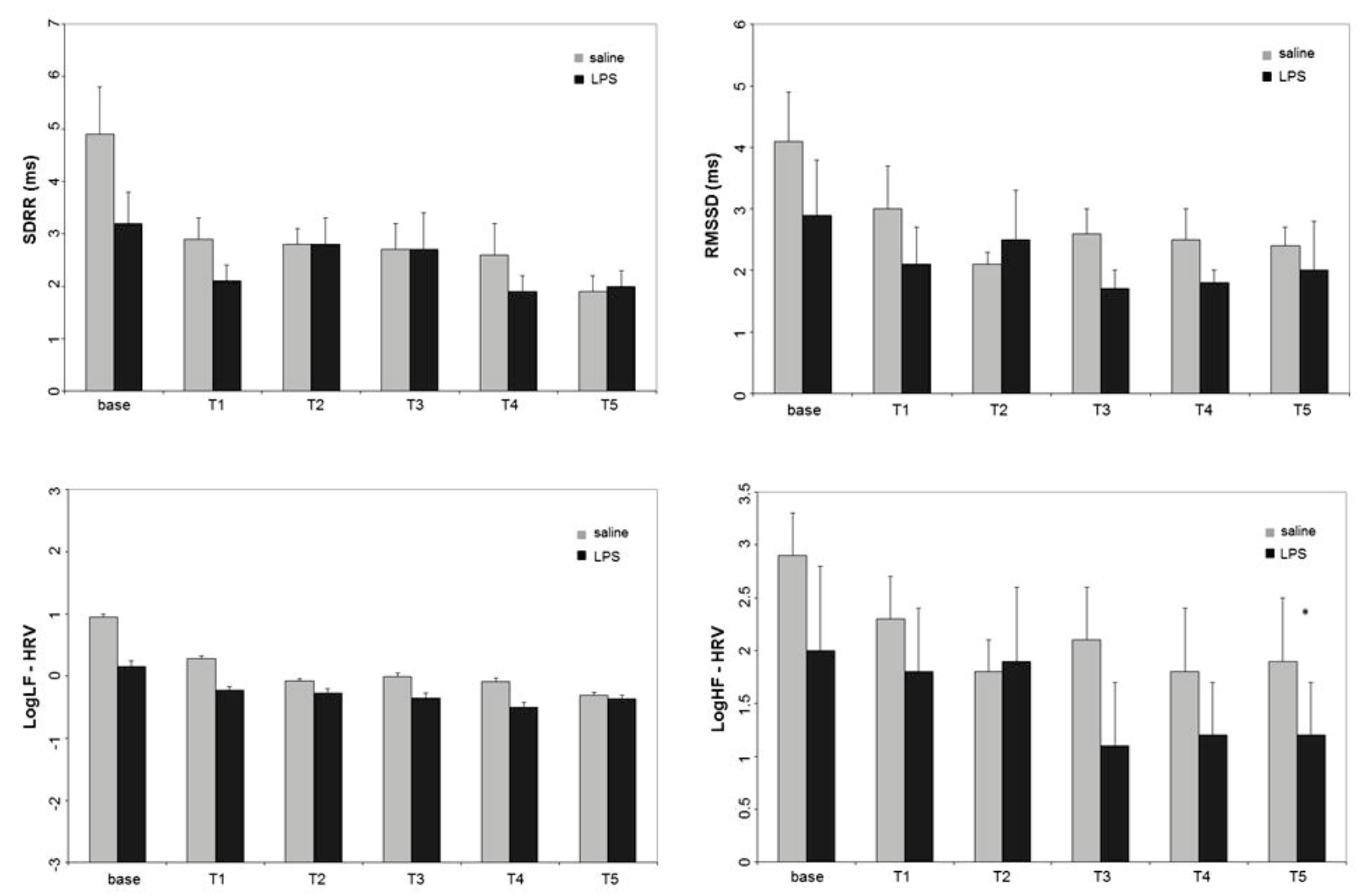

Fig 3. SDRR, RMSSD, logLFpower and logHFpower before saline/LPS administration (base) and 60, 120, 180, 240 and 300 min - T1, $\mathrm{T} 2, \mathrm{~T} 3, \mathrm{~T} 4, \mathrm{~T} 5$ after saline/LPS administration. $* \mathrm{P}<0.05$.

\section{Cardiovascular parameters}

LPS-induced endotoxemia in rats elicited a significant continuous increase in the heart rate demonstrated by shortening of R-R intervals (Fig. 2). In LPS group, heart rate accelerated from initial 306 beats/min up to 385 beats/min at $300 \mathrm{~min}$ after LPS administration $(\mathrm{P}<0.05)$. Between-groups, differences
(LPS vs. saline) were found during all analyzed intervals after administration of LPS/saline (T1-T5).

Variables of HRV: SDRR did not exhibit any significant change during development of endotoxemia, neither in comparison with saline controls. No significant differences were found in RMSSD and logLFpower in LPS group compared to controls. The linear HRV 
analysis revealed significantly reduced spectral power in $\mathrm{HF}$ band of animals with endotoxemia, namely logHFpower was decreased at the maximum temperature of $38.5^{\circ} \mathrm{C}$ at $300 \mathrm{~min}$ after endotoxin injection (LPS group: $1.2 \pm 0.5$ vs. $1.9 \pm 0.6$ in controls, ${ }^{*} \mathrm{P}<0.05$ ) (Fig. 3).

\section{Respiratory parameters, blood gases and $\mathrm{pH}$}

The initial values of respiratory parameters did not differ between the groups. In controls $\mathrm{V}_{\mathrm{T}}$ before and after experiment was unchanged $(1.8 \pm 0.2 \mathrm{ml}$ vs. $1.7 \pm$ $0.2 \mathrm{ml} ; \mathrm{P}>0.05)$ as was the respiratory rate $(102 \pm 12$ breaths per minute; bpm vs. $110 \pm 13$ bpm; $P>0.05$ ). In LPS group, minute ventilation progressively increased with elevation of body temperature (Table 1) as a result of significant increase in respiratory rate from baseline $100 \pm 12 \mathrm{bpm}$ to $238 \pm 18 \mathrm{bpm}(\mathrm{P}<0.01)$ at $300 \mathrm{~min}$ after LPS administration. Tidal volume in LPS animals was reduced to $1.3 \pm 0.3 \mathrm{ml}$ (at T5) in comparison with baseline value $(1.9 \pm 0.3 \mathrm{ml}$, $\mathrm{P}<0.05)$. No significant differences were present in absolute values of $\mathrm{PaO}_{2}, \mathrm{PaCO}_{2}$ and $\mathrm{pH}$ between LPS and control groups or in values compared to baseline. At 300 min after LPS administration $\mathrm{PaCO}_{2}$ tended to decrease but the drop was not significant (data not shown).

Table 1. Minute ventilation ( $\mathrm{ml} / \mathrm{min}$ ) in animals before saline/LPS administration (base) and 60, 120, 180, 240 and $300 \mathrm{~min}-\mathrm{T} 1$, T2, T3, T4, T5 after saline/LPS administration.

\begin{tabular}{lll}
\hline & Saline & LPS \\
\hline Base & $184 \pm 11$ & $189 \pm 12$ \\
$T 1$ & $183 \pm 9$ & $222 \pm 21^{*}$ \\
$T 2$ & $185 \pm 13$ & $251 \pm 25^{* *}$ \\
$T 3$ & $190 \pm 16$ & $318 \pm 24^{* *}$ \\
$T 4$ & $187 \pm 14$ & $322 \pm 22^{* *}$ \\
$T 5$ & $187 \pm 12$ & $309 \pm 19^{* *}$ \\
\hline
\end{tabular}

For between-group comparisons: saline vs. LPS: $* \mathrm{P}<0.05$, $* * \mathrm{P}<0.01$

Table 2. Biochemical parameters at the end of experiment 300 min after saline/LPS administration.

\begin{tabular}{lcc}
\hline & Saline & LPS \\
\hline TBARS $(\mathrm{nmol} / \mathrm{mg})$ & $6.6 \pm 1.8$ & $13.4 \pm 2.2^{*}$ \\
Aldosterone & $446.5 \pm$ & $1079.8 \pm$ \\
$(\mathrm{pg} / \mathrm{ml})$ & 118.3 & $112.8^{* *}$ \\
TNF- $\alpha(\mathrm{pg} / \mathrm{ml})$ & $8.49 \pm 0.53$ & $8.52 \pm 0.50$ \\
$I L-6(\mathrm{pg} / \mathrm{ml})$ & $8.0 \pm 0.6$ & $26.4 \pm 4.8^{* *}$ \\
\hline
\end{tabular}

\section{Biochemical markers and cytokine assays}

In the LPS group, higher level of TBARS in plasma, compared to the controls $(\mathrm{P}<0.05)$, demonstrated oxidation process at the systemic level (Table 2).

Aldosterone concentration was increased in LPS animals. Similarly, increased IL-6 was found in heart tissue homogenates of LPS rats (Table 2). No significant differences were found in TNF- $\alpha$ plasma levels between control and LPS rats.

\section{Discussion}

Systemic administration of lipopolysaccharide causes a well-characterized pathophysiological response including tachycardia and fever, but effects of endotoxin on HRV are not well described. According to some clinical studies, HRV analysis might have an important role in continuous monitoring strategies that could allow early diagnosis of severe infection (Moorman et al. 2006, Griffin et al. 2007, Fairchild et al. 2009).

In our study, there were differences in spectral analysis of HRV between rats with and without endotoxemia. Reduced HF power during endotoxemia could indicate a decrease in vagal tone, and it is consistent with other studies (Crandall et al. 2000, Matthew et al. 2004). Response to LPS-induced endotoxemia was accompanied by significant change in breathing pattern resulting in gradual rise in ventilation mainly through enhanced respiratory rate and a drop in tidal volume. It is well known that breathing pattern has strong effect on low-frequency as well as respiratory frequency R-R interval power spectra in human (Brown et al. 1993) and this appears to be a possible explanation of reduced spectral power in HF band in our animal experiments. However, increased ventilation has been found even $120 \mathrm{~min}$ after LPS administration, although decrease in HF power was observed only five hours of endotoxemia. Thus, we might speculate about other mechanisms attributing to observed drop in vagal activity in rats with endotoxemia.

The autonomic nervous system and the inflammatory response are very closely related (Kox et al. 2011). Systemic inflammation is characterized by the endocrine release of different cytokines: tumor necrosis factor, IL-1, IL-4, IL-6, IL-10 and many others (Koj 1996, Sporn 1997). They may induce activation of immunomodulatory responses mediated by both divisions of the autonomic nervous system (Haensel et al. 2008, Rosas-Ballina et al. 2008, Straub et al. 2008). Recently, it 
has been shown that the central nervous system can decrease cytokine production via parasympathetic activity and as a result of these findings, connection between vagus nerve and immune system has been named the cholinergic anti-inflammatory pathway (Borovikova et al. 2000, Tracey 2002, van Westerloo et al. 2006). The vagus nerve cholinergic signaling interacts with immune cells and inhibits TNF- $\alpha$, IL-1, IL-6 production (Wang 2004). Our results partly confirm previously reported inverse correlation between HRV indices and various biomarkers of inflammation (Tateishi et al. 2007, Tonhajzerova et al. 2013). TNF- $\alpha$ plasma levels did not exhibit significant change between controls and LPS animals $5 \mathrm{~h}$ after endotoxin administration. Fairchild et al. (2009) report peak expression of TNF- $\alpha 1 \mathrm{~h}$ post-LPS and its successive drop resulting to non-significant difference $6 \mathrm{~h}$ after endotoxin administration. Authors also provide an evidence supporting linking IL-6 (peaking $3 \mathrm{~h}$ post-LPS) to HRV depression. In our study, IL-6 was increased 300 min after LPS administration and HRV exhibited reduced power in HF band. That is partly consistent with study of Tateishi (2007) who demonstrated negative correlations with both LF and HF power values indicating a possible association between low HRV indices and hyper-cytokinemia. On the contrary, in another study Papaioannou et al. (2009) did not observe any correlation between IL-6 and HRV parameters. It suggests pleuripotency of this cytokine possessing both pro-inflammatory and anti-inflammatory features at the same time. Kox et al. (2011) also reported no HRV-cytokines association and moreover, according to these authors HRV analysis might not be an appropriate method to evaluate activation of the cholinergic anti-inflammatory pathway. Interpreting our data, we cannot confirm a significant correlation between magnitude of HRV and IL-6 level. SDNN values did not show significant change in rats with endotoxemia when compared to controls. It is surprising, because the inverse association between inflammation and total HRV is reported in the most severe cases. In our LPS model, considering duration of experiment, body temperature and biochemical markers we can speculate about its severity and possible multiorgan failure.

In conclusion, our results suggest altered HRV during systemic administration of endotoxin to rats particularly observed in frequency domain measures. Depression in HF component may indicate a neurocardiac vagal modulation and decreased cardiovagal function during LPS-induced endotoxemia. This is associated with increased cytokine production (IL-6) and might contribute to better understanding of vagal-immune interactions involved in cholinergic anti-inflammatory pathway.

\section{Conflict of Interest}

There is no conflict of interest.

\section{Acknowledgements}

Authors thank D. Kuliskova, Z. Remisova, Ing. Hutko and Ing. Petraskova for technical assistance. The study was supported by projects APVV-0435-11, APVV-023512 and GUK/32/2015.

\section{References}

AKSELROD S, GORDON D, UBEL FA, SHANNON DC, BERGER AC, COHEN RJ: Power spectrum analysis of heart rate fluctuation: a quantitative probe of beat-to-beat cardiovascular control. Science 213: 220-222, 1981.

BOROVIKOVA LV, IVANOVA S, ZHANG M, YANG H, BOTCHKINA GI, WATKINS LR, WANG H, ABUMRAD N, EATON JW, TRACEY KJ: Vagus nerve stimulation attenuates the systemic inflammatory response to endotoxin. Nature 405: 458-462, 2000.

BROWN TE, BEIGHTOL LA, KOH J, ECKBERG DL: Important influence of respiration on human R-R interval power spectra is largely ignored. J Appl Physiol_75: 2310-2317, 1993.

CRANDALL CG, ZHANG R, LEVINE BD: Effects of whole body heating on dynamic baroreflex regulation of heart rate in humans. Am J Physiol Heart Circ Physiol 279: H2486-H2492, 2000.

FAIRCHILD KD, SAUCERMAN JJ, RAYNOR LL, SIVAK JA, XIAO Y, LAKE DE, MOORMAN JR: Endotoxin depresses heart rate variability in mice: cytokine and steroid effects. Am J Physiol Regul Integr Comp Physiol 297: R1019-R1027, 2009.

GOLDSTEIN DS, BENTHO O, PARK MY, SHARABI Y: Low-frequency power of heart rate variability is not a measure of cardiac sympathetic tone but may be a measure of modulation of cardiac autonomic outflows by baroreflexes. Exp Physiol 96: 1255-1261, 2011. 
GRIFFIN MP, LAKE DE, O'SHEA TM, MOORMAN JR: Heart rate characteristics and clinical signs in neonatal sepsis. Pediatr Res 61: 222-227, 2007.

HAENSEL A, MILLS PJ, NELESEN RA, ZIEGLER MG, DIMSDALE JE: The relationship between heart rate variability and inflammatory markers in cardiovascular diseases. Psychoneuroendocrinology 33: 1305-1312, 2008.

JAVORKA M, TRUNKVALTEROVA Z, TONHAJZEROVA I, JAVORKOVA J, JAVORKA K, BAUMERT M: Short-term heart rate complexity is reduced in patients with type 1 diabetes mellitus. Clin Neurophysiol 119: 1071-1081, 2008.

KOJ A: Initiation of acute phase response and synthesis of cytokines. Biochim Biophys Acta 1317: 84-94, 1996.

KOX M, RAMAKERS BP, POMPE JC, VAN DER HOEVEN JG, HOEDEMAEKERS CW, PICKKERS P: Interplay between the acute inflammatory response and heart rate variability in healthy human volunteers. Shock 36: 115-120, 2011.

MALIK M, BIGGER JT, CAMM AJ, KLEIGER RE, MALLIANI A, MOSS AJ, SCHWARTZ PJ: Heart rate variability. Standards of measurement, physiological interpretation and clinical use. Eur Heart J 17: 354-381, 1996.

MATTHEW CB, BASTILLE AM, GONZALEZ RR, SILS IV, HOYT RW: Heart rate variability as an index of physiological strain in hyperthermic and dehydrated rats. J Therm Biol 29: 211-219, 2004.

MIONI C, BAZZANI C, GIULIANI D, ALTAVILlA D, LEONE S, FERRARI A, MINUTOLI L, BITTO A, MARINI H, ZAFFE D, BOTTICELLI AR, IANNONE A, TOMASI A, BIGIANI A, BERTOLINI A, SQUADRITO F, GUARINI S: Activation of an efferent cholinergic pathway produces strong protection against myocardial ischemia/reperfusion injury in rats. Crit Care Med 33: 2621-2628, 2005.

MOKRA D, TONHAJZEROVA I, MOKRY J, DRGOVA A, PETRASKOVA M, CALKOVSKA A, JAVORKA K: Rapid cardiovascular effects of dexamethasone in rabbits with meconium-induced acute lung injury. Can $J$ Physiol Pharmacol 86: 804-814, 2008.

MOKRA D, TONHAJZEROVA I, PISTEKOVA H, VISNOVCOVA Z, MOKRY J, DRGOVA A, REPCAKOVA M, CALKOVSKA A: Short-term cardiovascular effects of selective phosphodiesterase 3 inhibitor olprinone versus non-selective phosphodiesterase inhibitor aminophylline in a meconium-induced acute lung injury. J Physiol Pharmacol 64: 751-759, 2013.

MOORMAN JR, LAKE DE, GRIFFIN MP: Heart rate characteristics monitoring for neonatal sepsis. IEEE Trans Biomed Eng 53: 126-132, 2006.

PAPAIOANNOU V, PNEUMATIKOS I, MAGLAVERAS N: Association of heart rate variability and inflammatory response in patients with cardiovascular diseases: current strengths and limitations. Front Physiol 4: 174, 2013.

ROSAS-BALLINA M, OCHANI M, PARRISH WR, OCHANI K, HARRIS YT, HUSTON JM, CHAVAN S, TRACEY KJ: Splenic nerve is required for cholinergic antiinflammatory pathway control of TNF in endotoxemia. Proc Natl Acad Sci U S A 105: 11008-11013, 2008.

SPORN MB: The importance of context in cytokine action. Kidney Int 51: 1352-1354, 1997.

STRAUB RH, GRUM F, STRAUCH U, CAPELLINO S, BATAILLE F, BLEICH A, FALK W, SCHÖLMERICH J, OBERMEIER F: Anti-inflammatory role of sympathetic nerves in chronic intestinal inflammation. Gut 57: 911-921, 2008.

TATEISHI Y, ODA S, NAKAMURA M, WATANABE K, KUWAKI T, MORIGUCHI T, HIRASAWA H: Depressed heart rate variability is associated with high IL-6 blood level and decline in the blood pressure in septic patients. Shock 28: 549-553, 2007.

TONHAJZEROVA I, ONDREJKA I, CHLADEKOVA L, FARSKY I, VISNOVCOVA Z, CALKOVSKA A, JURKO A, JAVORKA M: Heart rate time irreversibility is impaired in adolescent major depression. Prog Neuropsychopharmacol Biol Psychiatry 39: 212-217, 2012.

TONHAJZEROVA I, MOKRA D, VISNOVCOVA Z: Vagal function indexed by respiratory sinus arrhythmia and cholinergic anti-inflammatory pathway. Respir Physiol Neurobiol 187: 78-81, 2013.

TRACEY KJ: The inflammatory reflex. Nature 420: 853-859, 2002. 
VON BORELL E, LANGBEIN J, DESPRÉS G, HANSEN S, LETERRIER C, MARCHANT-FORDE J, MARCHANTFORDE R, MINERO M, MOHR E, PRUNIER A, VALANCE D, VEISSIER I: Heart rate variability as a measure of autonomic regulation of cardiac activity for assessing stress and welfare in farm animals a review. Physiol Behav 92: 293-316, 2007.

VAN WESTERLOO DJ, GIEBELEN IA, MEIJERS JC, DAALHUISEN J, DE VOS AF, LEVI M, VAN DER POLL T: Vagus nerve stimulation inhibits activation of coagulation and fibrinolysis during endotoxemia in rats. J Thromb Haemost 4: 1997-2002, 2006.

WANG H, LIAO H, OCHANI M, JUSTINIANI M, LIN X, YANG L, AL-ABED Y, WANG H, METZ C, MILLER EJ, TRACEY KJ, ULLOA L: Cholinergic agonists inhibit HMGB1 release and improve survival in experimental sepsis. Nature Medicine 10: 1216-1221, 2004.

ZILA I, MOKRA D, JAVORKA M, JAVORKA K, CALKOVSKA A: Lipopolysaccharide-induced fever alters HeringBreuer reflex in anesthetized rats. J Therm Biol 37: 475-478, 2012. 